\title{
Monomarentalidad e imaginarios de género en contexto migratorio: Punto de vista epistemológico feminista en el estudio de las migraciones
}

\author{
Single motherhood and gender imaginaries in migratory \\ contexts: A standpoint feminist epistemology for \\ the study of migrations
}

\author{
Macarena Trujillo Cristoffanini \\ Universidad de Playa Ancha, Chile \\ macarenatrujilloc@gmail.com (CHILE) \\ Elisabet Almeda Samaranch \\ Universidad de Barcelona
}

Recibido: 25.10 .2016

Aceptado: 05.04.2017

\section{RESUMEN}

El presente artículo propone un acercamiento crítico al estudio de las migraciones desde la epistemología feminista del punto de vista, con el fin de comprender el peso de las estructuras de género en la experiencia migratoria. Se realiza una investigación cualitativa para explorar los imaginarios de género en mujeres latinoamericanas que actualmente residen en Barcelona y lideran hogares monomarentales, analizando sus posibles transformaciones en relación a las experiencias vividas en el contexto migratorio. Los principales resultados indican que existe una reformulación de los imaginarios tradicionales de género, que si bien no cuestionan de raíz las bases tradicionales asociadas a la femineidad, sí inciden en sus experiencias de maternidad y sus vivencias como mujeres en contexto migratorio. Así, se considera que las experiencias de migración potencian la movilización hacia perspectivas menos tradicionales de la femineidadmaternidad, configurándose como una vivencia empoderadora para las mujeres. 


\title{
PALABRAS CLAVE
}

Epistemología feminista, migraciones, género, monomarentalidad.

\begin{abstract}
This article proposes a critical approach to the study of migration from feminist epistemology point of view, in order to understand the weight of gender structures in the migration experience. A qualitative research is done to explore imaginary of gender in Latin American women that currently living in Barcelona and that are single-mother, analyzing possible changes in relation to the experiences in the immigration context. The main results indicate that there is transformations of traditional gender imaginary, while not questioning the traditional bases root associated with femininity, do affect their experiences of motherhood and their experiences as women in migratory context. Thus, it is considered that migration experiences enhance mobilization towards less traditional views of femininity and motherhood, configured as an empowering experience for women.
\end{abstract}

\section{KEY WORDS}

Feminist epistemology, migration, gender, single motherhood

\section{INTRODUCCIÓN}

En las últimas décadas se ha destacado la importancia de integrar el enfoque de género en el estudio de las migraciones (Gregorio Gil 1998, 2002; Instraw 2008), siendo que las rupturas con las perspectivas clásicas han provocado un giro hacia la integración del enfoque feminista; reafirmando la necesidad de incluir los factores de género para comprender los flujos migratorios y sus consecuencias socioculturales (Mummert 2010; Rodríguez García 2010). En este sentido, se ha considerado cómo las experiencias migratorias de hombres y mujeres son distintas no sólo en las motivaciones que movilizan la migración, sino también en las experiencias y vivencias que esta decisión conlleva.

De este modo, por medio de una investigación de corte cualitativo ${ }^{1}$, este artículo aborda en las experiencias de mujeres migrantes latinoamericanas que actualmente lideran familias monomarentales en Barcelona, explorando si,

${ }^{1}$ La investigación que se presenta en este artículo ha sido realizada en el marco del proyecto de investigación "Familias monoparentales del nuevo siglo. Retos y dilemas en tiempos de cambio" (CSO2011-29.889), dirigido por Elisabet Almeda, y desarrollado por el grupo de investigación consolidado COPOLIS-"Bienestar, Comunicación y Control Social” de la Universidad de Barcelona liderado por Almeda y del que forma parte Macarena Trujillo, ambas autoras de este artículo. 
una vez arribadas y viviendo en el país de destino, existe una transformación o re-composición de los imaginarios de género, específicamente en aquellos que relacionan con las nociones de maternidad y femineidad. Este foco nos permite ahondar en un tema que ha sido señalado de fundamental relevancia en los estudio de género y migraciones: conocer, desde la voz de sus protagonistas, cómo la experiencia migratoria puede formularse como factor de empoderamiento y/o flexibilización de los patrones de género tradicionales en relación al país de origen (Zentgraf 2002, Giorguli e Itzigsohn 2006).

En este sentido, apuntamos a que la epistemología del punto de vista feminista $^{2}$ (Harding 1996) es un aporte fundamental para integrar al estudio de las migraciones desde el enfoque de género; pues visibiliza experiencias sociales que tienden a estar desvalorizadas y otorga espacio al relato de la experiencia contextualizada en los espacios cotidianos que viven las personas; $\mathrm{y}$, en este caso, de mujeres migrantes latinoamericanas que lideran familias monomarentales.

\section{EPISTEMOLOGÍA FEMINISTA DEL PUNTO DE VISTA EN EL ESTUDIO DE LAS MIGRACIONES}

Las dinámicas migratorias de Latinoamérica hacia España, han estado relacionados con los procesos económicos de ajuste estructural, reflejados en el empobrecimiento de su población y aumento de las desigualdades sociales entre sus habitantes, impacto que ha sido vivenciado con mayor fuerza por las mujeres, materializando la feminización de los circuitos alternativos (Sassen en Pedone y Gil Araújo 2008).

En esta línea, se ha resaltado el peso de las mujeres en los flujos migratorios, subrayando la relevancia de abandonar antiguos preceptos androcéntricos en los cuales se entendían a las mujeres migrantes como "acompañantes" de los varones, ya sean padres o maridos. Consecuentemente, cuando se aborda la feminización de las migraciones, debe atenderse a las construcciones de género así como al patriarcado en tanto sistema de organización social (Solé 2000), teniendo la precaución de no esencializar a las mujeres migrantes, considerando la heterogeneidad de las mujeres en el marco de la multiplicidad de países y condiciones de origen (Solé 2000, Instraw, 2008, Contreras y Trujillo 2017).

En términos de la experiencia migratoria, las mujeres vivencian una triple discriminación: por razones de género, de etnia/raza y económica o de clase (Juliano 2000; Solé 2000; Parella 2003). Así, Solé (2000) declara que esta triple

${ }^{2}$ Se debe tener en cuenta que este enfoque ha recibido diversas denominaciones según las autorías y sus correspondientes traducciones, siendo los más utilizados: enfoque del punto de vista, enfoque del punto de vista feminista, punto de vista de las mujeres o punto de vista epistemológico feminista; por lo cual en el marco de esta investigación se tratarán indistintamente, tal como lo hace Harding (1996) en su libro Ciencia y feminismo, dado que en este texto se aúnan y nombran de manera organizada las principales autoras y reflexiones vinculadas a este enfoque. 
discriminación se manifiesta en el mercado de trabajo, altamente generizado y marcado por la etnicidad; así como por la invisibilidad que experimentan tanto en la vida social.

Es importante destacar que las causas económicas empujan a muchas mujeres a iniciar un proyecto migratorio; sin embargo, diversas experiencias dan cuenta de que algunos de estos proyectos también son propiciados por otras razones, como aquellas que se basan en la búsqueda de mayor autonomía en el país de destino (Solé 2000). Este sería el caso de mujeres que quieren finalizar relaciones de pareja en las que estaba presente la violencia de género o cuyo objetivo es experimentar mayor libertad en el marco de las estructuras sociales de género del país de origen (Correa Pereira 2014; Trujillo, Rivera y Almeda 2015).

De este modo, en los estudios de las migraciones necesariamente debe incluirse un enfoque de género, cobrando central relevancia la noción del punto de vista epistemológico feminista, perspectiva que da cuenta de la invisibilización de la experiencia femenina en la producción de conocimiento científico tradicional. Así, dicho enfoque epistémico, destaca cómo socialmente se han cancelado la experiencia femenina, planteando la necesidad de transformar las líneas androcéntricas de conocimiento, visibilizando las vivencias de las mujeres y comprendiendo cómo éstas se interrelacionan con las estructuras sociales del género, de clase, etnia, etc. En este sentido, trata las implicancias del sexismo y androcentrismo en el propio quehacer científico (Harding 1996; Maffia 2010), convocando a constituir investigaciones cuyas temáticas aborden la vida de las mujeres en diversos contextos sociales y culturales.

Tal como señala Smith (2012), el punto de vista de las mujeres es una forma de conocimiento que concibe la experiencia como palabra de autoridad en sí misma, enfocándose en el mundo de las mujeres invisibilizado bajo el supuesto "sujeto universal masculino". De este modo, se entiende como una perspectiva de investigación que trabaja con las experiencias que dan forma a la vida de las personas, para comprender las dimensiones sociales que hay más allá de las propias experiencias. Así, se concentra en las realidades cotidianas, para posteriormente comprender todas aquellas interconexiones de esas acciones con las relaciones de dominación. Justamente, en esta propuesta se apuesta por "conocer las actividades de las personas reales situadas en lugares y en tiempos locales y concretos son reconocidas por ellas mismas" (p.24); las que se pueden comprender desde la investigación en cuanto se producen en el lenguaje como habla y/o texto.

Por su parte, Harding (1996) propone que por medio de la mirada y voz de las mujeres, la ciencia pueda plantearse desde una óptica no dualista ni hegemónica y, de este modo, abrirse hacia nuevas perspectivas. Así, la propuesta se comprende como una postura política cuyo horizonte es analizar las relaciones sociales de poder y dominación así como las estructuras mentales y simbólicas que la sostienen. El análisis que Harding realiza, le permite afirmar que hasta ahora, sólo se ha narrado una historia parcial: la de los varones, por lo cual la 
socialización de género patriarcal ha conllevado que el conjunto de integrantes de la sociedad considere las actividades que realizan las mujeres como reflejo de la naturaleza y no como una práctica social y cultural.

Estas dimensiones de la vida, son las que la teoría e investigación feminista han sabido comprender no sólo como una lógica de producción material, sino como aquella que ha servido de soporte para el desarrollo de las dinámicas sociales, permitiendo tanto el desenvolvimiento básico y cotidiano de los seres humanos así como las macro relaciones económicas y políticas (Rubin 1996). Por lo cual, tal como señala Rivera (2003), dar vida pública a la experiencia de las mujeres es una de las tareas que ha emprendido y debe seguir desarrollando el feminismo.

\section{IMAGINARIOS DE MATERNIDAD Y FEMINEIDAD DESDE LA EXPERIENCIA MIGRATORIA}

Consecuentemente con los elementos afirmados, planteamos que la integración epistémica feminista enriquece el estudio del campo de las migraciones. En este sentido, consideramos que la investigación sobre mujeres que lideran familias monomarentales en contexto migratorio, da cuenta de la relevancia de abordar dinámicas sociales que se han enmarcado dentro de "lo privado"; pero que, basándonos en la epistemología del punto de vista feminista, comprendemos de central relevancia tanto para el campo de las migraciones como de los estudios de género. Este factor es de especial relevancia considerando que la presente investigación trata la interseccionalidad ${ }^{3}$ de las estructurales sociales que experimentan migrantes latinoamericanas al frente de hogares monomarentales. En este sentido, la intersección entre los estatus adscritos (género, etnia) y los adquiridos (clase, inmigrante) configurarán las experiencias de las mujeres que constituyen el colectivo en investigación.

En base a lo anterior, presentamos los principales resultados de una investigación de corte cualitativo en la cual se abordaron temáticas de monomarentalidad, género y migración.

El estudio se llevó a cabo en la ciudad de Barcelona con un total de catorce entrevistas $^{4}$, realizadas durante el primer semestre de 2015. Se entrevistaron a mujeres migrantes latinoamericanas (independiente de si su estatuto jurídico es irregular, regular o nacionalizada) residentes en Barcelona y que lideran familias

${ }^{3}$ Tal como señala Stolcke (2010), el concepto de intersección alude a la interrelación entre dos o más elementos, los cuales una vez reunidos mantienen sus elementos originarios así como también emerge una conjunción de nuevas situaciones producto de dicha interacción.

${ }^{4}$ Las entrevistas se realizaron utilizando una pauta abierta, la que se construyó en relación a los objetivos de investigación así como en la utilización de dos materiales de apoyo. El primero son las recomendaciones y la pauta de entrevista realizada por Hays (1998) en su libro "Las contradicciones culturales de la maternidad". El segundo fue la Encuesta sobre monoparentalidad y Diversidad Familiar, EMODIF, la que es parte del proyecto de investigación mencionado "Familias monoparentales del nuevo siglo. Retos y dilemas en tiempos de cambio" (véase nota al pie 1). 
monomarentales, con al menos un/a hija dependiente, menor de dieciocho años y viviendo en la ciudad de destino. Por otro lado, se consideraron diversas variables para dar heterogeneidad a la muestra, entre ellas: país de origen, edad, años de inmigración, número de hijos/a, edad de los hijos/as, nivel instrucción formal, y ocupación. Las formas de contacto con las entrevistadas fueron la vinculación directa con la Federación de familias monoparentales de CatalunyaFEFAMOCA, el contacto con grupos y talleres de mujeres inmigrantes en Barcelona y también técnica de bola de nieve.

Cabe destacar que trabajamos con la técnica de entrevistas cualitativas, puesto que es una herramienta que permite profundizar en las experiencias del colectivo en investigación, así como tratar experiencias íntimas, por lo cual se propicia mayor confianza a la hora de expresar sus vivencias y/o opiniones (Valles 2009); más aún, en el marco del tratamiento de experiencias complejas (Juliano 2004) . Así, se apeló a constituir la relevancia de dinámicas sociales invisibilizadas, para posteriormente interpretar desde la experiencia de las propias entrevistadas, las vivencias relativas a monomarentalidad e inmigración, otorgando a la experiencia el estatus de fuente de conocimiento. De este modo, la comprensión de lo vivido no se erige en una dinámica de investigación que apela al descubrimiento, a constituir como inteligible a un objeto inferiorizado (Comesaña 2008); sino como aquella relación que reconoce autoría y autoridad en las múltiples personas que interactúan en el proceso investigativo; especialmente cuando se apela al conocimiento situado que no pretende afirmaciones universales desde la óptica vertical, sino conexiones parciales que sea realizan de la vida de las personas (Gandarías y García, 2014).

Por otra parte, destacamos que para los fines de esta investigación entendemos por familia monomarental cuando una mujer "gestiona un hogar sin pareja estable conviviente o sin que ésta se haga cargo de sus corresponsabilidades, independientemente de cuál sea el estado civil de esta persona" (Di Nella 2011:36). El uso del término monomarentalidad dice relación directa con evidenciar que la mayor parte de familias monoparentales son lideradas por mujeres; por lo cual, tal como indican Almeda y Di Nella (2011a) la dimensión de género es imprescindible para abordar las experiencias y realidades de estas familias; y, así mismo, es necesario construir estrategias -como son las nuevas denominaciones- para materializar una identificación adecuada con el grupo social al que se nombra ya que "si las mismas realidad sociales las contemplamos y nombramos desde la experiencia femenina, nos representarán un imaginario social distinto" (p.95).

${ }^{5}$ A estos elementos se puede agregar que las entrevistas fueran realizadas por una de las investigadoras, la cual en el momento de la realización del trabajo de campo, también vivenciaba la experiencia de ser madre y migrante latinoamericana. En este sentido, se compartían factores de género, etnicidad y origen sociocultural por lo cual tal como han señalado diversas autorías, se potencia la posibilidad generar relaciones de confianza en la diada de investigación (Oakley 1981, Broom, Hand y Tovey 2009). De este modo, se pueden apreciar ventajas al compartir características espaciales e históricas con las participantes de una determinada investigación (Cotteril 1992, Ali 2012). 
M. TRUJILLO, E. ALMEDA MONOMARENTALIDAD E IMAGINARIOS DE GÉNERO...

\begin{tabular}{|c|c|c|c|c|c|c|c|c|}
\hline \multirow{8}{*}{ 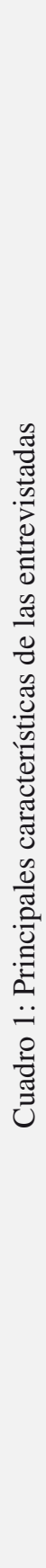 } & 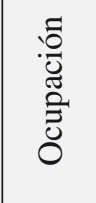 & 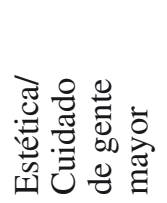 & 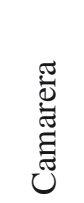 & 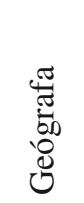 & 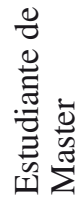 & 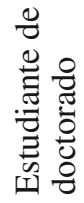 & 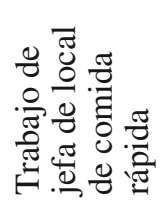 & 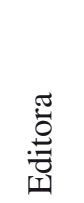 \\
\hline & 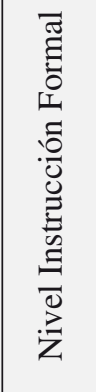 & 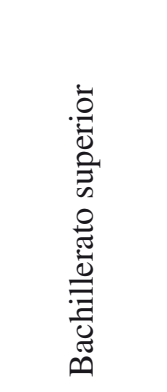 & 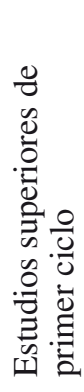 & 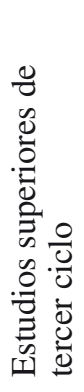 & 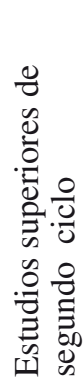 & 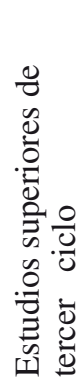 & 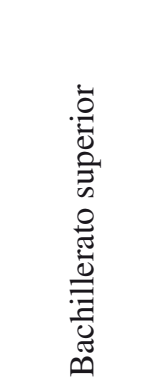 & 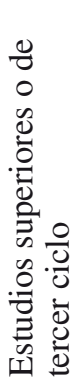 \\
\hline & 苞 & 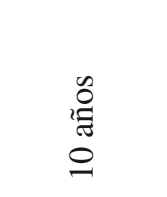 & $\begin{array}{l}\mathscr{0} \\
\infty \\
\infty \\
\infty\end{array}$ & 兽 & $\begin{array}{l}0 \\
\text { ?̊̃ } \\
0 \\
0\end{array}$ & 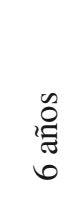 & 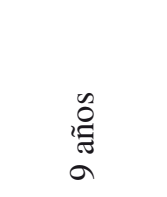 & 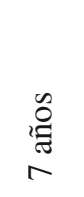 \\
\hline & 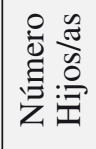 & $: \stackrel{\frac{\pi}{\Xi}}{=}$ & 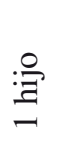 & $: \frac{\pi}{\exists}$ & $\stackrel{\circ}{:}$ & : & $\stackrel{ }{:}$ & 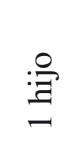 \\
\hline & 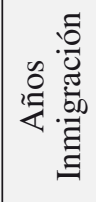 & 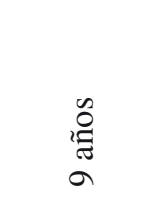 & 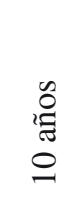 & 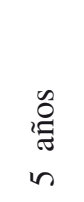 & - 这 & 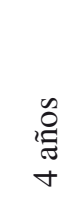 & 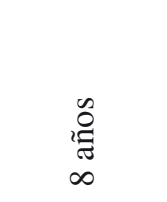 & 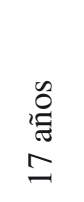 \\
\hline & 苞 & n & শি & ○ & m & m & 乞 & 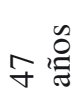 \\
\hline & 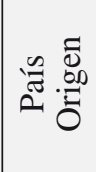 & $\frac{\stackrel{0}{ت}}{\ddot{U}}$ & 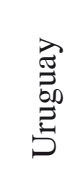 & $\frac{\ddot{Z}}{\ddot{U}}$ & $\frac{\frac{\pi}{0}}{\frac{0}{0}}$ & $\frac{\ddot{n}}{\frac{\pi}{U}}$ & 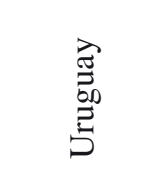 & $\begin{array}{l}\frac{\pi}{0} \\
\frac{0}{N} \\
0 \\
D \\
D\end{array}$ \\
\hline & 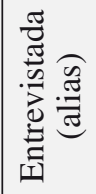 & $\begin{array}{l}\stackrel{n}{\Xi} \\
\stackrel{-}{\Xi}\end{array}$ & 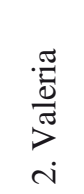 & 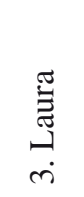 & 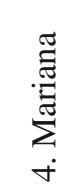 & 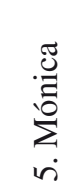 & $\begin{array}{l}\frac{\pi}{\tilde{U}} \\
\dot{U} \\
\dot{0}\end{array}$ & 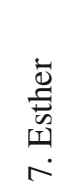 \\
\hline
\end{tabular}




\begin{tabular}{|c|c|c|c|c|c|c|c|}
\hline 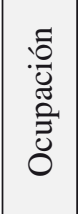 & 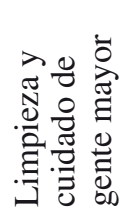 & 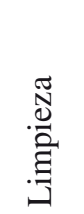 & 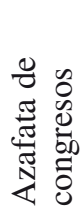 & 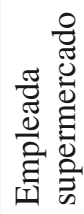 & 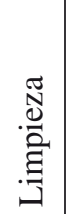 & 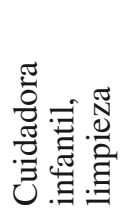 & 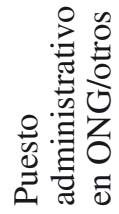 \\
\hline 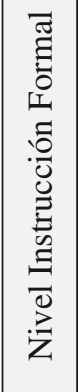 & 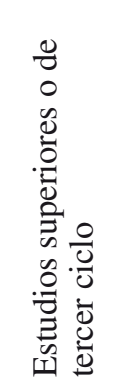 & 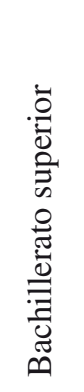 & 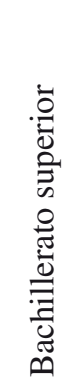 & 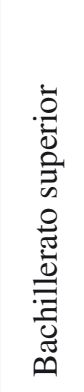 & 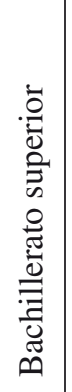 & 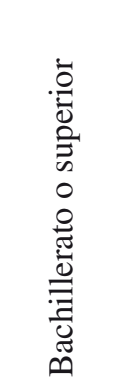 & 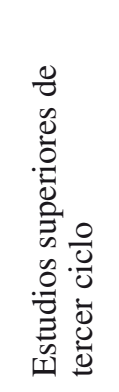 \\
\hline 苞 & 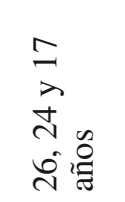 & 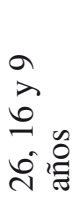 & $\begin{array}{l}\stackrel{0}{0} \\
\text { : } \\
a\end{array}$ & 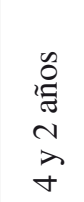 & 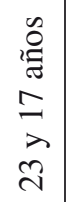 & 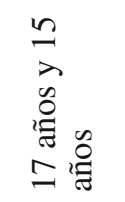 & 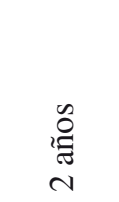 \\
\hline 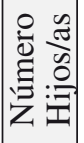 & 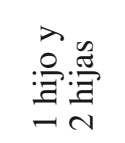 & 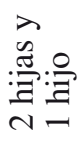 & $\stackrel{\circ}{:}$ & 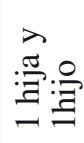 & 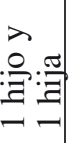 & 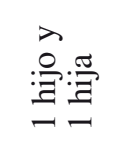 & $: \frac{\sigma}{\Xi}$ \\
\hline 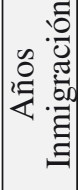 & 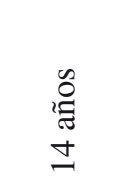 & $\begin{array}{l}0 \\
\stackrel{0}{\Xi} \\
n \\
n\end{array}$ & 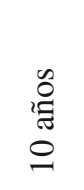 & 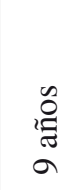 & $\begin{array}{l}\text { ô } \\
\text { ఏ્త } \\
0 \\
0\end{array}$ & 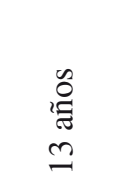 & 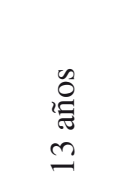 \\
\hline 胥 & 芯总 & ケ产 & Әे & - & n & $\hat{n} \stackrel{0}{0}$ & ఫ跑 \\
\hline \begin{tabular}{cc}
0 & 0 \\
$\cdots$ & 0 \\
\hdashline & 0 \\
0 & 0
\end{tabular} & 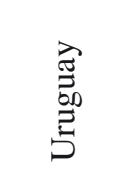 & $\frac{\stackrel{0}{\Xi}}{\circlearrowright}$ & 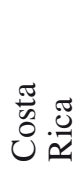 & $\frac{\stackrel{0}{ت}}{\circlearrowright}$ & $\frac{\ddot{Z}}{\ddot{U}}$ & 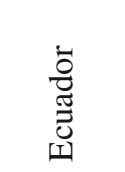 & $\begin{array}{l}\frac{\pi}{0} \\
\stackrel{0}{0} \\
\stackrel{0}{0} \\
>\end{array}$ \\
\hline 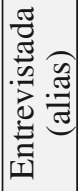 & 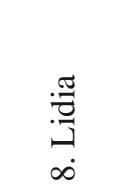 & $\begin{array}{l}\stackrel{\frac{\pi}{3}}{\Xi} \\
\dot{a}\end{array}$ & 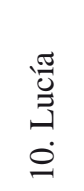 & 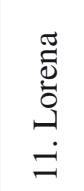 & 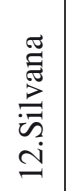 & 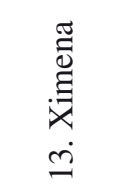 & $\begin{array}{l}\stackrel{N}{\Xi} \\
\stackrel{\Xi}{ \pm} \\
\oplus \\
\dot{ \pm}\end{array}$ \\
\hline
\end{tabular}


Destacamos que en el contexto de las entrevistadas, las vías de entrada a la monomarentalidad, son particularmente dos. La primera, es la entrada sin vínculo de pareja -a través de relación sexual esporádica, violación o inseminación artificial- siendo que en todos estos casos, la monomarentalidad se vivencia desde el país de origen. Se resalta que en esta categoría, la migración es motivada desde una dimensión subjetiva y no como respuesta a condiciones económicas a superar.

La segunda vía de entrada responde al cese de la relación sentimental, o sea a la ruptura de la pareja, siendo que hay mujeres que se separaron o divorciaron tanto en el país de origen como de destino. En las experiencias de las mujeres que entraron a la monomarentalidad una vez arribadas al país de destino, no es el proyecto migratorio el que desestabiliza la relación biparental, sino que son las propias falencias de dinámicas inequitativas de género dentro del núcleo de la pareja -ya sea por desigual reparto de las responsabilidades del hogar y crianza o por violencia machista- las que las determinan a finalizar la relación siendo que, una vez ocurrido esto, los padres no se corresponsabilizan de la crianza de los hijos e hijas y/o de la manutención de éstos/as.

Con todo lo anterior, en el presente artículo desarrollamos los principales resultados de investigación enfocados en los discursos de las entrevistadas en relación a cuatro ejes de análisis:

- Imaginarios de maternidad y su vinculación con los constructos tradicionales de género y la biologización del maternaje;

- Concepciones de femineidad, atendiendo a sus continuidades y transformaciones en el marco de la experiencia migratoria

- Imágenes con que las propias mujeres vivencian la monomarentalidad, enfatizando sus estigmas y potencialidades; y finalmente,

- Violencia de género, apuntando a cómo la experiencia migratoria puede resultar como un factor promotor para finalizar relaciones en la que se experimenta violencia machista.

\subsection{Imaginarios de maternidad y la primacía de la biología: La naturalización social de la maternidad}

En relación al primer eje de análisis, en el discurso de las entrevistadas se pudo analizar una primacía de la imagen de maternidad como reflejo de la naturaleza femenina, invocándose de forma directa la relación entre embarazo y amor innato hacia los hijos e hijas. Esta vinculación entre gestación y amor maternal, refleja la presencia de la biologización de la maternidad y su enquistamiento en los imaginarios de las mujeres. 
"Porque bueno, siempre como pienso todo en el sentido biológico -risasno sé...como que siempre tuve el instinto de querer ser madre, no sé, quizás la necesidad de querer compartir tu vida con una persona que siempre...bueno, no es lo mismo que los padres, pero como la necesidad de crear tu propia familia (...) un proyecto de vida además de decir que egoísta sería de mi parte, si pensara solamente en desarrollarme profesionalmente, sin compartir metas, pero sin compartirlo con alguien, ese era mi pensamiento en ese tiempo " (Mónica, Entrevista 5).

“(...) Lo bueno es que soy madre, soy feliz porque mi hijo me dio una felicidad que no sé, a esa edad no se entendía" (Clara, Entrevista 6).

De este modo, emergen los atributos asignados a la maternidad de forma tradicional, concibiéndose como aquella experiencia que entrega una plenitud particular. Así, se comprende la capacidad reproductiva y la propia práctica del maternaje, como objetivo vital para las mujeres. Estas ideas se soportan en una base particular: la concepción del instinto maternal como sostén de la identidad femenina (Badinter 1984), el cual es un componente clave de la maternidad tradicional (Tubert 1991):

"Yo creo que es algo más fisiológico, biológico, hormonal...-risas-que claro como lo llevas en el vientre, luego tienes que darle leche hay ese apego que con el hombre nunca se va a dar, si bien el hombre sabe que es su hijo, la madre siempre lo va a dar todo por el hijo y siempre el hijo va a ser la prioridad, pero a veces el hombre no es así" (Mónica, Entrevista 5).

"Sí, es que yo le decía a él \{marido yo tengo miedo de qué hacer cuando nazca la bebe o sea qué es lo que tengo que hacer... o de no tener paciencia porque no tenía paciencia... no me aguantaba ni yo misma... y él me dijo mira cuando el niño nace.... es que te nace un instinto y es toda la verdad, eso es verdad (...) yo creo que cuando nació la niña florece el instinto maternal" (Lorena, Entrevista 11).

La naturalización de la maternidad, tal como señala Tubert (1991), vincula un hecho biológico -como lo es la reproducción- con la práctica social del maternaje, lo que resulta en la materialización de una determinada "ideología de género" (Maquieira 2000). Así, se construye un orden simbólico en torno a la maternidad que le hace prácticamente incuestionable. Este hecho es precisamente lo que se ha venido destacando por diversas teóricas feministas (Lerner 1990; Osborne 1993; Palomar 2004) donde se subraya que dicha naturalización ha sido la piedra angular por medio de la cual se ha constituido la maternidad como una política de control de género (Nash 2010).

No obstante, es necesario señalar que dentro de esta lógica existen algunos puntos divergentes, en los cuales se entrevé algunas desmitificaciones de la biología como destino, matices que se presentan especialmente en la valoración de aquellas mujeres que deciden no tener hijos/as: 
"Yo creo que es un vínculo, o sea que no es ningún estado biológico, no, que es un proyecto de vida y que dependiendo de cómo tú te lo plantees puedes tener un proceso de calidad (...) (Mariana, Entrevista 4).

A pesar de estos matices, se visualiza en el discurso la presencia de la supuesta escisión entre mujer y madre, anteponiendo la maternidad ante cualquier otro deseo que pueda surgir en el marco de situaciones vitales:

“(...) Yo creo que eso también es importante eh...para mí ser madre implica ser madre y luego ser mujer, no al revés ¿sabes? Y creo que conocer a alguien tres meses y que te diga ya vente a vivir conmigo y ¿qué dices? Tengo una nena, no., pues sola posiblemente sí (...)” (Iris, Entrevista 1).

Consecuentemente, se aprecia la idea de sacrificio como componente central de la maternidad en la cultura latinoamericana (Montecino 1997; Stevens 1974, Smith Silva 2014), el cual se comprende como un valor:

"Dar todo por sus hijos, que te quitas de todo, dejas de ser mujer, todo, por los hijos, que no les pase nada, por ejemplo yo cuando mis hijos salen yo no me duermo pensando ¿qué es lo que va a pasar? (...) Por ejemplo si tengo dinero en lugar de comprar ropa para mí, lo compro para mis hijos, yo no quiero llevar a una persona a mi casa porque no quiero que mis hijos estén incómodos y siempre me sacrifico por ellos yo" (Silvana, Entrevista 12).

Por otra parte, es interesante que siendo las entrevistadas mujeres con responsabilidades no compartidas, en las que la gran mayoría de ellas recibe una cantidad de dinero muy baja o simplemente inexistente por parte del padre de su hijos/as, no destaquen la relevancia de ser el principal sostén económico de la familia. Este punto da cuenta que se siguen subrayando las características socialmente vinculadas a las madres y a la división sexual del trabajo imperante, como lo son las tareas de cuidado, cariño y atención al mundo doméstico/reproductivo, y no la totalidad de las que en la práctica realizan, como es el rol económico de proveedoras principales o únicas que tienen bajo su responsabilidad.

En esta misma línea, en el discurso se establece la noción de las mujeresmadres como irremplazables en la crianza de su progenie, siendo que los hombres-padre se entienden como sustituibles. Si bien se puede afirmar que esta situación cobra sentido en contexto de monomarentalidad y migración, la problemática es que esta indispensabilidad se basa en las supuestas características naturales de mujeres y hombres, es decir, en la naturalización social de la maternidad:

"Porque tiene a los niños y los niños han salido de uno...de hecho es muy diferente el trato que le da una mamá al papá, la mujer hace mil cosas a la vez, la mujer lo sabe todo... el hombre... sólo te hace una cosa a la vez, científicamente está comprobado así y Dios los creo así, la mujer llega mucho más allá que lo que llega el hombre" (Lorena, Entrevista 11). 
“(...) Una de las cosas ahora que recuerdo, que me llamo mucho la atención, cuando yo vine con la nena acá y ¿la trajiste sola? como que no entendían porque yo no la dejé (...) como que aquí era normal que las emigrantes vinieran a trabajar y le mandaran el dinero a sus familias, y yo pues no, porque un hijo tiene que estar con su madre, de hecho los padres pueden ser reemplazables, eso sí que es verdad" (Iris, Entrevista1).

Es relevante tener en cuenta que las entrevistadas consideran de manera positiva a aquellas mujeres que no quieren tener hijos/as como opción de vida; situación que puede considerarse como un aumento de la flexibilidad de la supuesta concatenación lógica entre mujer y maternidad; sin embargo, esta disminución de prejuicio hacia mujeres que no tienen hijos/as pierde flexibilidad una vez que se tienen, entrando en juego nuevamente las prescripciones normativas de la maternidad.

\subsection{Concepciones de la feminidad: continuidades y transformaciones en el marco de la experiencia migratoria}

Es interesante comprender que los imaginarios antes comentados no son estáticos y se ven recompuestos por las experiencias vitales y el contexto en que se despliegan. Así, en el segundo eje de análisis relativo a las concepciones de feminidad, se establece que la migración es un claro componente desestabilizador, permitiendo construir nuevos relatos- que si bien no cuestionan las bases de los imaginarios tradicionales de maternidad y feminidad - sí tienen la capacidad de re-componerlos y readecuarlos en base a la experiencia vivida.

Así, si bien la idea de que la maternidad es parte del "ser mujer" está presente en el discurso de la mayor parte de las entrevistadas; se aprecia que estos relatos se matizan a medida de que se insertan en una nueva realidad cultural en el país de destino:

"Yo es que siempre he pensado cuando he encontrado personas que no quieren tener niños digo al menos uno...no sé...algo que te salga de ti... el día de mañana tener un hijo al menos, pero hoy en día pienso diferente porque eso va a decisión de la persona si quieres o no tener, si quieres o no ser madre, viene de ti (...) es que me ha cambiado la forma de pensar... allá tenemos los hijos por tener al marido al lado (...) acá tienen los hijos porque realmente quieren tenerlo (Ximena, Entrevista 13)".

“(...) Veo que acá la gente vive de otra forma -risas-como que allá desde pequeños como que tenemos la cultura de que es una prioridad tener hijos, una prioridad casarte, una prioridad tener pareja, pero aquí, veo que la gente está un poco más relajada, que se toma más su tiempo, que hace todo más tranquilamente, paso a paso" (Mónica, Entrevista 5). 
De este modo, las entrevistadas comprenden la experiencia migratoria como un proceso vital que ha generado cambios en sus perspectivas con respecto a su entorno e incluso sobre sí mismas.

"Yo creo que la madurez está dentro de la inmigración, o sea obviamente el haber permanecido en Venezuela durante este tiempo, o sea estos años que he estado aquí, allá mis procesos hubiesen sido completamente diferentes, porque claro, el tema cultural pesa un montón, obviamente el haber estado aquí, que es otra cultura completamente diferente y a pesar de que ha habido momentos bastante heavy y la presión, la integración, creo que de alguna manera esa lejanía ha facilitado mis transformaciones" (Esther, Entrevista 7).

Es importante establecer que si bien la experiencia migratoria se suele valorar de forma positiva, puede implicar una serie de vivencias que son bastante duras, entre ellas está el aislamiento y la soledad:

"A ver, yo soy una persona diabética, dependiente de insulina, operada dos veces y hace poco estuve una semana en el hospital, hace tres meses (...) esa semana se quedó con una amiga mi hijo, y yo ahí sola, ¿tú crees que alguien vino a verme?, nadie... yo llegué con la ropa... y con el pijama del hospital... no tuve a nadie que me llevara una bata....unas chanclas....nada, entones esas cosas tú después los analizas y dices joder, estoy sola, estás sola, sola" (Julia, Entrevista 9).

"A veces lo más negativo, es la falta de apoyo más que nada, la soledad, la soledad es algo muy duro con lo que a veces se aprende a vivir" (Mónica, Entrevista 5).

Aun así, se comprende que el contexto migratorio ha otorgado herramientas que han posibilitado tomar decisiones vitales que en el país de origen no hubiesen materializado. De este modo, las entrevistadas destacan que encontrarse fuera de contextos sociales y familiares de carácter conservador les ha permitido poner fin a relaciones de pareja insatisfactorias:

"No, no estaba enamorada porque ya habíamos tenido un montón de problemas, yo estaba más con él por mi familia, mi familia no aceptaba un divorcio, mi padre era muy antiguo no quería que yo me divorciara" (Silvana, Entrevista 12).

"A veces cuando llegaba a casa se daba cuenta de las cosas mi madre, entonces le dije mamá me quiero ir a trabajar fuera, no sé el futuro que me espera con mi marido y voy a ir, voy a ahorrar un poco de dinero, para que el día de mañana me tengo que separar de él yo tenga dinero, esa era la idea y me dijo mi hija te apoyo" (Lidia, Entrevista 8).

En este sentido, tal como indica Bastia (2009), se afirmar la dimensión generizada de las migraciones, ya que las estructuras de género -y las relaciones de poder que éstas acarrean- permean todas la experiencia migratoria; desde el proyecto hasta la propia movilidad trasnacional, destacándose que "la migración 
puede y de hecho influye en las relaciones de género, pero de maneras complejas y a menudo contradictorias" (p.73).Por lo cual, al integrar el enfoque de género en los estudios de las migraciones, se ha evidenciado que la percepción sobre la experiencia migratoria es distinta para varones y mujeres; siendo que para éstas tiende a implicar un avance en términos de estatus y autonomía de las estructuras de género en comparación a su contexto de origen (Zentgraf 2002; Giorguli e Itzigsohn 2006).

De este modo, emerge la idea de ser mujer y una nueva mirada con respecto a lo que dicha afirmación implica; aun así, si bien en primera instancia esta noción pudiese parecer contradictoria con la concepción de "ser madre antes que mujer", es interesante notar cómo esta transformación les ha permitido llevar adelante la monomarentalida, siendo el motor de fuerza para lidiar con todas las dificultades propias de ser la única persona a cargo de todas las responsabilidades del hogar y de la crianza de sus hijos e hijas.

En el marco de esta anteposición de la maternidad en relación a otras identidades, se resalta que existe una afirmación de sus propias necesidades y la búsqueda -aunque sea mínima- de espacios propios fuera de las actividades de madre. Para lograr este fin, se generan múltiples estrategias, entre las que destacan -para las mujeres que comparten vivienda- contar con la ayuda de las otras personas con las que conviven en el hogar; de este modo, pueden salir y realizar actividades recreativas o de ocio:

"Lo dejo en la noche en casa, con el compañero de piso y me desaparezco (...) más que nada es por la confianza, por las cosas, todo se trabaja, todo se da y permisos que uno se dé también ¿no? el mayor factor principal es el permiso que uno se da para esas cosas, porque antes yo tenía la capa de súper madre (...) y que una madre tenía que estar ahí ante todo, sobre todo y abnegada y bueno dejando de lado un montón de cosas y sí le sumabas madre y pareja, eso ya era una explosión" (Valeria, Entrevista 2).

Estas prácticas si bien pueden parecer nimias, implican una dificultad y un esfuerzo constante para aquellas mujeres monomarentales e inmigrantes; pues generalmente no cuentan con familia que colabore con la crianza, lo que implica que los tiempos dedicados a ésta den como resultado un aislamiento de la vida social, siendo una experiencia especialmente absorbente (Almeda, Di Nella y Obiol 2008).

De hecho, esta situación conlleva a que se generen prácticas que pueden ser cuestionadas por el entorno, pero que las mujeres consideran deben realizar en el contexto propio de la monomarentalidad:

"Ya con el tiempo, más grandecito, seis años por ejemplo, entre semanas, ya me voy a ir al cine, entonces él se quedaba solo en la casa y decía listo, yo te espero porque la independencia ha sido la tendencia para que él se sepa manejar solo, entonces, de hacer se quedaba programado, jugaba muñequitos, veía televisión y yo llegaba y hacíamos la comida y ya pues el resto de la 
rutina y ahoritica pues que está más grande ya lo hago también, pero eso siempre lo hacía sin decirle a mucha gente porque o si no me preguntaban cómo, pero porqué” (Mariana, Entrevista 4).

En este sentido, emerge con claridad el hecho que la maternidad implica estar sometidas de forma constante al cuestionamiento de "buena y mala madre". Esto es significativo en un imaginario que tiene tantas prescripciones como lo es la maternidad, siendo esta una situación que vivencian todas las mujeres como parte de la lógica de la maternidad patriarcal como política de control de género (Nash 2010) y de la función pedagógica que ejerce el estigma de "mala madre" (Juliano 2004) ${ }^{6}$. Es más, las madres monomarentales tienden a estar en tela de juicio con mayor frecuencia por el estigma asociado a este tipo de conformación familiar (Walters 1996, Juliano 2011, Almeda, Di Nella y Ortiz 2014).

Sin embargo, si bien anteriormente se apreció en el discurso de las entrevistadas la persistencia del imaginario tradicional de maternidad, existe una concepción más flexible con respecto a la dicotomía "buena y mala madre".

"Depende mucho de la situación, porque una buena madre para mi es la que vela por sus hijos y hay diferentes formas de velar por tus hijos, puedes ser una ladrona pero lo eres porque le estas sacando la comida a tu hijo por ejemplo y para mí eso es una buena madre, no tiene nada que ver con... con... con los dictámenes sociales, sino que tiene que ver con cubrir las necesidades de tu hijo" (Beatriz, Entrevista 14).

"Buena madre, no hay madre perfecta, pero si buena madre, amar a tus hijos... lo demás improvisar (...) buena madre no hay, todas cometemos errores" (Lorena, Entrevista 11).

Esta situación da cuenta de que si bien se mantiene la idea de que la "buena madre" es aquella que procura el bienestar de sus hijos e hijas ante que de sí mismas, se entiende que pueden darse múltiples maneras para cumplir este objetivo, existiendo un reconocimiento explícito a las distintas formas de materializar la crianza.

En esta línea, se puede comentar que los imaginarios de género de las mujeres entrevistadas, transitan en un doble sentido, entre los denominados como autoesquema normativo y autoesquema no tradicional de género (Parella y Samper 2007). El primero, es aquel que responde a las determinaciones culturales de lo femenino en sociedades patriarcales, es decir a la vinculación al ámbito doméstico-privado y sus designios. En el segundo, se consideran los roles tradicionales de género como limitantes para el desarrollo personal, por lo cual existe cierta plasticidad en torno a dichos roles; por lo cual, quienes lo desarrollan, "disponen de una mayor flexibilidad y variabilidad conductual” (Martínez 2002, en Parella y Samper 2007:164).

${ }^{6}$ Si bien Juliano desarrolla dicho término para evidenciar el peso que el estigma de la prostitución ejerce en todas las mujeres como colectivo -cuyo fin es "advertirles" de las consecuencias de abandonar el rol tradicional de femenino dentro de la maternidad dentro del matrimonio y la pasividad sexual- se considera que esta "función pedagógica" puede aplicarse a los estigmas de género vinculados, en este caso, a la "mala madre" puesto que también implica una transgresión al rol esperado de las mujeres en el marco de la feminidad patriarcal. 


\subsection{Imágenes sobre la monomarentalidad: Estigmas y potencialidades}

La construcción social que equipara la maternidad como dimensión constitutiva de la identidad femenina, está presente en las prescripciones ideológicas y es interiorizada por las mujeres de carne y hueso. Así, como tercer eje de análisis comprendemos que las familias monomarentales han sido altamente estigmatizadas, pues se han valorado desde la lógica de la carencia paternal y, por tanto, señaladas como poco aptas para la crianza (Walters 1996a; Almeda 2004; Almeda, Di Nella y Obiol 2008), lo que paradójicamente no ocurría del mismo modo en aquellas familias que entraban a la monomarentalidad por la vía de la viudez. Este hecho denota que no se trata de problemas reales si no presiones institucionales y sociales (Juliano 2011), siendo que dicha situación se puede explicar por la desestabilización que las monomarentalidades generan en las bases ideológicas de la familia tradicional (Almeda y Di Nella 2011b)

“(...) Fue fuerte porque yo era la nieta mayor, la mujer mayor en mi familia extensa, entonces hubo un tema de presión social, de mal ejemplo, que eso no se tenía que hacer, que eso no se hacía, entonces ese tema creo que fue el más fuerte que yo tuviera un hijo sola (...)" (Mariana, Entrevista 4).

En este contexto, las entrevistadas señalan que si bien en los países de origen ser monomarental es la tónica de muchas mujeres, siguen siendo tachadas de forma negativa:

"Allá es más cómo pobrecita quizás, aquí se vincula con una decisión y allá es como oh una desgracia...no sé...lo que puedo pensar yo de acuerdo a lo que conozco, a mi gente, pero creo que allá se sigue viendo como que oh, es que te abandonaron" (Laura, Entrevista 3).

"Por eso te digo, porque son discursos que todavía no están aceptados, yo creo que si bien en Venezuela la monoparentalidad es criticada por el hecho de que, mira...la dejaron preñada" (Esther, Entrevista 7).

"Es mal mirado, típico como el estereotipo, pero además si es muy joven, seguro que juzgan a una madre soltera, que está frustrada, no supo llevar su matrimonio y se quedó sola por tonta, cosas asî" (Lorena, Entrevista 11).

Desde la noción de estigmatizaciones en el país de origen, las entrevistadas vislumbran que en el país de residencia actual, las mujeres vivencian menos restricciones y más posibilidades de movimiento en el marco de las estructuras de género, generándose un cambio dentro de la propia actitud:

"Yo creo que se les mira mal a las madre solteras, allá en Paraguay, aquí tu puedes salir a tomar una cerveza con un amigo, y nadie dice es un hombre, ese es un macho como dicen en mi país, en mi país te sientas a tomar una cerveza con un amigo y no, no puedes tener amigos, ese ya es tu amante, y 
menos si es casado, imagínate esas cosas son muy mal miradas, pero acá tu sabes que es distinto, a las mujeres solas con hijos no se les mira así de mal" (Lidia, Entrevista 8).

Aun así, si bien la concepción de familia se ha flexibilizado en el tiempo (San Miguel, 2015), estos estigmas siguen siendo vivenciados por las mujeres que son progenitoras con responsabilidades familiares no compartidas y el hecho de no tener pareja se suele considerar como una suerte de fracaso personal (Almeda 2004; Almeda, Di Nella y Obiol 2008)

Así mismo, las entrevistadas destacan cómo el entorno familiar y/o social del país de origen ha cuestionado su decisión de finalizar la relación de pareja; hecho que da cuenta de la primacía de la imagen de familia como objetivo social a alcanzar:

"Yo creo que sí, que en mi país cuestionan más, de hecho cuando yo me separé de mi ex, varias personas me lo cuestionaron ¿por qué? Que primero es la familia y claro allá soy un bicho raro (...)nunca me afectó mucho la verdad, por que como soy una persona de ideas fijas, si siento que una cosa está bien y me siento bien, me da lo mismo lo que digan los demás, pero sí, allá te estigmatizan más que acá (...) (Mónica, Entrevista 5).

"Si hay prejuicios, por ser madre soltera allí te miran mal, los mismos hombres dicen no quiero hacer pareja con esta porque ya tiene un hijo (Silvana, Entrevista 12)

Esta situación en que se estereotipa a las mujeres con hijos/as y sin pareja, se agudiza bajo las imágenes sociales atribuidas a las mujeres latinoamericanas; lo que ha sido experimentado en primera persona por muchas de las entrevistadas:

"Lo que pasa es que el haber llegado aquí hace 17 años, de alguna manera, cuando no había tanta inmigración latinoamericana y haber llegado con 30 años y con mucha independencia, me preparó a que eso de alguna manera podía suceder porque la gente me miraba con curiosidad, preguntaba sobre mí con curiosidad, los esposos o los novios de mis amigas me miraban así como... ésta te va a llevar por mal camino, al final ser mujer sin hombre, primero genera curiosidad y no una curiosidad constructiva, generalmente el chisme (...) Esther, Entrevista 7).

"Porque somos gente simpática, somos guapas...somos trabajadoras ¿cómo podemos estar sola? no tiene sentido (...) tienes que saber bailar (risas), eres simpática, profesional y seguro que tienes más de un novio" (Beatriz, Entrevista 14).

Es importante destacar que en las experiencias sociales pueden coexistir distintas etiquetas atribuidas a las personas, en razón de las diversas posiciones que éstas ocupen en la estructura social, siendo que en el caso del colectivo en investigación, se atribuyen estereotipos vinculados tanto a la femineidad normativa, como a la monomarentalidad y al origen latinoamericano. Aun así, estas etiquetas muchas veces pueden ser reconstruidas por las propias prácticas 
de las actoras sociales; y en este contexto, es vital el reconocimiento de los elementos positivos y potencialidades implicados en experiencias que escapan a la imagen social de normalidad.

De este modo, se aprecia que muchas de las entrevistadas comprenden que dentro de su familia se generan dinámicas que no se darían en un contexto de biparentalidad, sumándose la riqueza propia que conlleva la experiencia migratoria. Es decir, si bien han vivenciado estigmas asociados a la monomarentalidad y/o las dificultades propias de vivir fuera del país de origen y lejos del soporte de las redes familiares; por otro lado, evidencian cómo estas situaciones pueden constituirse como fortalezas, ya sea por el estrechamiento de lazos madre-hijo/a o por la generación de dinámicas horizontales y cooperativas dentro del mismo núcleo familiar:

"Yo creo que la ha fortalecido, o sea el hecho que yo esté sola, que no tengamos a nadie más de la familia aquí ha fortalecido mucho más la relación y unidad" (Mónica, Entrevista 5).

Entendiendo el contexto migratorio como aquel proceso que implica vivir en un país que no es el natal, con dinámicas culturales propias y distintas a la sociedad de origen; afirmamos que para muchas entrevistadas este nuevo contexto les permite vivenciar la maternidad desde nuevas lógicas. En la práctica, esta situación apareja la posibilidad de flexibilizar las estructuras de género que constriñen decisiones vitales $\mathrm{y}$, en este caso, vinculadas a la monomarentalidad:

"Es verdad lo rompe todo, porque entonces ¿qué pasa? Nuestra cultura latinoamericana es muy de pareja, muy de hogar convencional (...) de alguna manera, si algo puede haber facilitado mi monoparentalidad aquí, es que bueno, aquí tu vez que las parejas no se casan (...)" (Esther, Entrevista 7).

Ahora bien, es interesante cómo estas reconfiguraciones sociales pueden ser un arma de doble filo para la vida de las mujeres, ya que esta situación incrementa las demandas y expectativas con respecto a este colectivo. De esta forma, tal como señala Juliano (2011), no se aumentan las políticas sociales para apoyar a este colectivo, si no que se espera que "la madre soltera tiene que poder con el trabajo fuera, con la carga familiar, con la crianza de los niños, con todo, sin necesidad de demasiadas ayudas, lo cual, no sólo es irreal, sino que también termina siendo muy duro" (p.85).

\subsection{Violencia de género: El potencial emancipador de la experiencia migratoria}

Por último, en el cuarto eje de análisis de este artículo, y en el marco de las entrevistas realizadas, se puede apreciar que todas las mujeres que entraron a la monomarentalidad por relaciones donde existía violencia de género, se dieron en el país de destino, incluso habiéndola vivenciado en el país de origen. 
Esta situación da cuenta de un hecho relevante; es la migración a un país como España donde existe mayor conciencia mediática y legal con respecto a ésta, donde las mujeres cuestionan con mayor fuerza este tipo de prácticas por parte de sus (ex)parejas. Con esto, se entiende que es la experiencia migratoria un proceso que permite tener más autonomía para salir de relaciones desiguales en el ámbito de la pareja y, en este sentido, se puede afirmar su componente emancipador en el marco de las relaciones de género.

La violencia vivenciada puede ser sicológica, física o ambas; sin embargo -en cualquiera de sus variantes- constituye un factor de gran estrés y vulnerabilidad en la vida de las mujeres que la experimentan:

"Cada vez era peor, llegó un momento que él le pegaba a mis hijos por cualquier cosa, por tonterías y yo me metía a defenderlos y él me insultaba... me decía de todo... vivir todos los días era así, peleas... (...) (Silvana, Entrevista 12).

Estas diversas manifestaciones de la violencia machista, generan inseguridad, baja autoestima, temor y sentimientos de soledad y aislamiento; los que se amplifican en un contexto de migración. Sin embargo, a pesar de las propias dinámicas del denominado círculo de la violencia, estas mujeres logran cuestionar la calidad de vida que llevaban. Así, más allá de las dificultades propias que conlleva dejar una relación en el contexto ya señalado, se asumen obstáculos que van de la mano con el enfrentamiento a la violencia de género:

"Sí, yo tenía mi piso...precioso...con todas mis cosas...y salir de ahí con dos maletas y empezar de cero (...), así que imagínate, me cambió la vida, económicamente, pero personal también nos cambió a mejor, porque llevábamos una vida muy mala, muchas discusiones en la casa... lo pasamos muy mal...entonces...yo prefiero tener lo que tengo ahora... en material....pero la vida que llevo ahora prefiero eso... porque ahora respiro...tengo libertad... antes yo vivía mucho el maltrato de él, sus gritos, hasta orden de alejamiento tuve (Julia, Entrevista 9).

De este modo, deciden poner fin a estas relaciones de dominación, siendo una vivencia compleja pero a la vez liberadora. Por un lado, está el deseo de terminar la relación, pero se asume que en un contexto migratorio las posibilidades de subsistencia económica son más difíciles, sobre todo en aquellas mujeres que en ese momento no contaban con residencia legal en España.

“(...) Pero yo le dije, yo pienso...si lo denuncio ¿cómo voy a vivir? no tengo nada, no tengo ni trabajo, ni papeles ni nada y me dice ella, la trabajadora social, de alguna forma te saldrá todo, denúncialo y ya me convenció y fuimos a los mossos d'esquadra (...)" (Silvana, Entrevista 12).

También hay casos en los cuales la violencia de género se manifiesta de manera posterior al cese de la convivencia, la que se denomina como violencia sobrevenida pues emerge con la finalización del vínculo (Bodelón, 2011), tal como se presenta en el siguiente relato: 
“(...) Entonces empezó a acosarme y tuve que ponerle una orden de alejamiento, una no, realmente fueron cuatro, me llamaba, me insultaba iba al trabajo cuando no le tocaba y bueno, así fue, y fue tanto el miedo y tan a la cara que al primer indicio de me querés quitar al niño, una denuncia, yo corto por lo sano...y así fue y fue cuando hice la denuncia (...) (Clara, Entrevista 6).

Aun así, con esto no se afirma que en España y en Cataluña las leyes contra la violencia hacia las mujeres ${ }^{7}$ no tengan fisuras; por el contrario, no es solo el marco social y legal el que empodera a estas mujeres; sino que se entiende la experiencia migratoria como propulsora de esta decisión en un contexto cultural distinto al de origen:

“(...) Porque después el papá de mis hijos que nunca dio un peso más para los niños ni nada, yo dije ¿qué voy hacer? sin papeles, sin casa ni nada, sin trabajo, y dije jolines, por más que pensaba... aquí te ofrecen mucho que denuncies y todo esto pero a la hora de la verdad cuando tienen que ayudar no hay ayuda" (Silvana, Entrevista12).

En este relato se entrevé que el apoyo legal para las mujeres que vivencian violencia de género, no siempre es el esperado por éstas, siendo que en la práctica no funciona tal y cómo es descrito en la ley. A esta situación, se puede agregar la violencia institucional y la fragmentación de los episodios de violencia que sucede en los juzgados por parte de funcionarios/as y jueces/as (Bodelón y Luna 2015).

\section{REFLEXIONES FINALES:}

En base a las significaciones que emanan del discurso de las entrevistadas, se afirma que migrar no es un hecho puntual, en el que se deja el país de origen para asentarse en un nuevo territorio; más bien, se entiende como un proceso de larga duración, que afecta las condiciones materiales de vida de las personas, pero también -y de forma particular- las subjetividades y las proyecciones de éstas en las decisiones y valoraciones sobre la vida cotidiana.

Con respecto a los imaginarios de género, en el discurso de las entrevistadas emerge la concepción biologicista del maternaje, atribuyendo a la maternidad características esencialistas reflejadas en las mujeres sólo por el hecho de serlo; destacando entre éstas: amor, cariño, cuidado a los otros/as, entrega desmedida, circunscripción al mundo familiar, etc. Desde esta lógica, aseveramos que los imaginarios de maternidad están en directa relación con las ideologías de género de una determinada sociedad, por tanto es primordial comprender cómo se materializan en la vida de las mujeres y desde qué bases se proyectan en su propia experiencia cotidiana, especialmente cuando la ideología de la maternidad

${ }^{7}$ Ley Orgánica 1/2004, de 28 de diciembre de Medidas de Protección Integral contra la Violencia de Género 
como reflejo del instinto femenino ha sido apuntada por las estudiosas feministas como una estrategia utilizada para mantener el statu quo de la lógica patriarcal y para la pervivencia de las prescripciones normativas de la femineidad tradicional (Badinter 1984, Lerner 1990).

Ahora bien, como resultados de esta investigación hemos podido develar cómo estos idearios han sido reformulados en el marco de las experiencias de monomarentalidad y migración que vivencian sus protagonistas; siendo que las imágenes de femineidad se transforman hacia patrones de género más flexibles, generando mayores espacios para la independencia y autonomía. Dicha transformación es clara cuando muchas de las entrevistadas afirman la sensación de liberación de ciertas pautas normativas que les constreñían en el país de origen y que son vivenciadas de distinta manera en el país de destino.

De tal manera, para el caso de este estudio, se apreció una bidireccionalidad en el discurso de las entrevistadas, emergiendo la convivencia entre el autoesquema normativo y autoesquema no tradicional de género señalados por Parella y Samper (2007). De esta forma, es importante subrayar que las participantes de esta investigación, han resquebrajado- no necesariamente de forma intencionada- los patrones clásicos de lo femenino tanto en el país de origen como de destino. Por una parte son migrantes y, por tanto, desacatan la norma de quietud y pasividad asociada a las mujeres, aventurándose a un viaje que la mayoría de las veces no tiene retorno agendado. Por otro lado, vivencian la monomarentalidad, lo que cuestiona la norma biparental de la familia y visibiliza el trabajo de la maternidad; trabajo invisible y socialmente desvalorizado.

En esta línea, se destaca cómo el contexto migratorio incide en la transformación de los imaginarios de género, pues si bien de forma general las mujeres siguen remarcando el ideario tradicional de maternidad, entienden que existen diversas maneras de ser madre, lo que en definitiva flexibiliza la función pedagógica del estigma de "mala madre" lo que les permite generar estrategias para tener espacios personales con menor grado de culpabilidad.

Así mismo, es destacable que si bien los estigmas adjudicados a la monomarentalidad siguen presentes; en la experiencia de las entrevistadas, se vivencian de una forma menos acusada que en el país de origen, pues se entiende que su contexto actual es más diverso en relación a las conformaciones familiares.

También, valoramos cómo las entrevistadas que vivenciaron violencia de género en el marco de sus relaciones de pareja o ex pareja, tomaron conciencia de esta situación y generaron prácticas que les permitieron desvincularse dichas relaciones, cesando el vínculo afectivo y realizando las denuncias pertinentes.

Por tanto, consideramos que tanto la experiencia migratoria como de monomarentalidad, movilizan transformaciones hacia una perspectiva menos tradicional de la maternidad y de la femineidad; lo que tiene implicancias directas en cómo las mujeres se ven a sí mismas, sus derechos y su lugar en el mundo.

Si bien es innegable que los constructos patriarcales y sus símbolos 
asociados constriñen el movimiento y la subjetividad de este colectivo; también se debe señalar que las mujeres generan estrategias de movimientos dentro de estos márgenes; siendo que para muchas de ellas la maternidad en contexto de monomarentalidad e inmigración, les permite sentir su autovalía y determinación para enfrentarse a situaciones vitales complejas y difíciles; por tanto, haciendo eco de las palabras de Barbieri (2008) la maternidad debe comprenderse desde un análisis que cubra distintos matices de ésta, pues la atribución de las competencias del maternaje por las propias mujeres se puede considerar como un ancla a estructuras tradicionales o, por el contrario, como una palanca de fuerza en las motivaciones vitales.

Así mismo, se pudo concluir que la migración se configura como una vivencia empoderadora para las mujeres; pues si bien, tal como señala Ali (2014), esta experiencia no implica necesariamente que se cuestionen las bases clásicas de roles de género y división sexual del trabajo, permite a las mujeres generar estrategias para resistir y flexibilizar dichas estructuras en sus cotidianeidades, especialmente considerando el antes y después del proyecto migratorio.

En esta línea, el presente artículo rescata la noción de epistemología del punto de vista en el estudio de la experiencia migratoria; pues permite comprender las atribuciones subjetivas de sentido a prácticas cotidianas; las que dan cuerpo a la vida de este colectivo de mujeres. Así, atendiendo la interseccionalidad de las estructuras y relaciones de poder que en estas experiencias se interconectan, afirmamos que este enfoque epistemológico es un aporte paradigmático en los estudios de género y migraciones.

\section{BIBLIOGRAFÍA}

ALMEDA, E. (Dir.) (2004): Les famílies monoparentals a Catalunya: perfils, necessitats i percepcions. Departament de Benestar i Família. Generalitat de Catalunya, disponible enhttp://ibdigital.uib.es/greenstone/collect/portal_social/archives/ gencat00/83.dir/gencat0083.pdf [Consulta 15-1-2016]

ALMEDA, E. DI NELLA, D. y OBIOL, S. (2008): “L'experiència de la monoparentalitat: percepcions, dificultats i demandes", Arxius de Sociologia, $\mathrm{N}^{\circ} 19$, pp. 19-29.

ALMEDA, E. y DI NELLA, D. (2011a): “Monoparentalidad, género y bienestar", en Bienestar, protección social y monoparentalidad. Las Familias monoparentales a debate, Volumen I, España: Ediciones Copalqui, pp. 93-123.

ALMEDA, E y DI NELLA, D. (2011b): "Hacia un enfoque integral de la monoparentalidad", en Familias monoparentales. Violencias, Discriminaciones y Vulnerabilidad. Las familias monoparentales a debate. Volumen V. España: Ediciones Copalqui, Pp. 17-30.

ALMEDA, E., Di NELLA, D. y ORTIZ, R. (2014): Perspectiva no androcéntrica en los estudios sobre familias monoparentales: Reflexiones e implicaciones metodológicas, disponible en http://atheneadigital.net/article/view/dinella-almedaortiz/1360- pdf-es. [Consulta 10-6-2015] 
ALI, R. (20014): "Empowerment beyond resistance:culturalways of negotiating power relations", en Women's Studies International Forum, 45, pp. 119-126.

BADINTER, E. (1984): ¿Existe el instinto maternal? Historia de amor maternal Siglos XVII al XX, España, Ediciones Paidos.

BARBIERI, P. (2008): Palabras que usan las mujeres para nombrar lo que hacen y viven en el mundo del trabajo. Cuadernos inacabados $\mathrm{N}^{\circ} 52$, Madrid, Editorial horas y horas.

BASTIA, T. (2009): "La feminización de la migración trasnacional y su potencial emancipatorio", Revista Papeles de Relaciones Ecosociales y Cambio Global, $\mathrm{N}^{\circ}$ 104, pp. 67-77.

BODELÓN, E. (2011): "Leyes de Violencia y monoparentalidad", en Las Familias monoparentales a debate, Volumén V, España: Ediciones Copalqui., pp. 31-38

BODELÓN, E. y LUNA, R. (2015): "Mujeres maltratadas en los juzgados: la etnografía como método para entender el derecho en acción", en Revista de antropología social, $\mathrm{N}^{\circ} 24$, pp. 105-126.

COMESAÑA, G. (2008): De métodos y filosofía feminista. Propuestas metodológicas y conceptuales desde el feminismo latinoamericano, Venezuela, Ediciones Universidad de Zulia.

CONTRERAS, P. y TRUJILLO, M. (2017): “Desde las epistemologías feministas a los feminismos decoloniales: Aportes a los estudios sobre migraciones",

disponible en http://atheneadigital.net/article/view/v17-n1-trujillo-contreras/1765pdf-es [Consulta 9-3-2017]

CORREA PERIRA, V. (2014): "Más allá de la racionalidad económica: una nueva aproximación para la compresión de la emigrante latinoamericana en Santiago de Chile", Revista de Estudios sociales, $\mathrm{N}^{\circ} 49$, pp.176-189.

DI NELLA, D. (2011): "Familias monoparentales: Hacia una conceptualización crítica desde la perspectiva de los derechos de la infancia", en Las familias monoparentales a debate Volumen III, Entre la ley y la experiencia: nociones y redes de familias monoparentales, España, Ediciones Copalqui, pp. 33-54.

GANDARIAS, I. y GARCÍA, N. (2014): "Producciones narrativas: una propuesta metodológica para la investigación feminista", en Otras formas de (re)conocer Reflexiones, herramientas y aplicaciones desde la investigación feminista, País vasco, Universidad del país Vasco, pp. 97-110.

GIORGULI, S. e ITZGSOHN, J. (2006): "Diferencias de género en la experiencia migratoria. Trasnacionalismo e incorporación de los migrantes latinos en Estados Unidos", disponible en http://www.scielo.org.mx/pdf/pp/v12n47/v12n47a2.pdf. [Consulta 10-12-2015].

GREGORIO GIL, C. (1998): Migración femenina: su impacto en las relaciones de género, España, Ediciones Narcea.

GREGORIO GIL, C. (2002): "Proceso migratorios y desigualdad de género", en Cuestiones de género en el fenómeno de las migraciones, Madrid, Universidad de Comillas, pp. 11-30.

HARDING, S. (1996): Ciencia y Feminismo; España, Ediciones Morata.

HAYS, S. (1998): Las contradicciones culturales de la maternidad, Barcelona, Editorial Paidós.

INSTRAW. (2008): Cruzando fronteras: Migración y desarrollo desde una perspectiva de género, España, Instituto de la mujer.

JULIANO, D. (2000): "Movilidad espacial de género", en Mujer y migración en el mediterráneo occidental, España, Editorial Icaria, pp. 305-318. 
JULIANO, D. (2004): Excluidas y Marginadas, Madrid, Serie Feminismos Ediciones Cátedra.

JULIANO, D. (2011): "Las familias monomarentales y la discriminación social", En Familias monoparentales. Violencias, Discriminaciones y Vulnerabilidad. Las familias monoparentales a debate. Volumen V, España, Ediciones Copalqui, pp. 79- 112.

LERNER, G. (1990): La creación del patriarcado, Barcelona, Ediciones crítica.

MAFFIA, D. (2010): "Contra las dicotomías, feminismo y epistemología crítica". En, Asociación Feminista La Cuerda, Asociación de mujeres Petén-YXQYK y Alianza política sector de mujeres. Epistemología feminista. Guatemala, Alianza. Pp. 73-82.

MAQUIEIRA, V. (2000): "Género, diferencias y desigualdad", en Feminismos: debates teóricos contemporáneos, Madrid, Alianza, 2000, pp. 127-190.

MONTECINO, S. (1997). Palabra dicha: escritos sobre género, identidades y mestizaje. Chile: Colección de Ciencias Sociales Universidad de Chile.

MUMMERT, G. (2010): "La crianza a distancia: representaciones de la maternidad y paternidad transnacionales en México, China, Filipinas y Ecuador", en Procreación, Crianza y Género: Aproximaciones antropológicas a la parentalidad, Barcelona, Promociones y Publicaciones Universitarias, pp. 167-190.

NASH, M. (2010): "Maternidad y construcción identitaria: debates del siglo XX", en Debates sobre la maternidad desde una perspectiva histórica. Barcelona, Editorial Icaria, pp. 23-49.

OSBORNE, R. (1993): La construcción sexual de la realidad, Madrid, Ediciones Cátedra.

PALOMAR, C. (2004): "Malas madres": construcción social de la maternidad, en Revista Debates Feministas. Año 15, Volumen 30, pp. 12- 34.

PARELLA, S. (2003): Mujer, inmigrante y trabajadora: la triple discriminación, Barcelona, Antrophos Editorial.

PARELLA, S. y SAMPER, S. (2007): "Factores explicativos de los discursos y estrategias de conciliación del ámbito laboral y familiar de las mujeres inmigradas no comunitarias en España", en: Revista Papers 85, pp. 157-175

PEDONE, C. y GIL ARAUJO, S. (2008): Maternidades trasnacionales entre América latina y el estado español. El impacto de las políticas migratorias en las estrategias de reagrupación familiar, en: Nuevos retos del transnacionalismo en el estudio de las migraciones, España: Ministerio de trabajo e inmigración, pp.149-177.

RIVERA, M. (2003): Nombrar el mundo en femenino: pensamientos de las mujeres y teoría feminista, España, Editorial Icaria.

RODRIGUEZ GARCÍA, D. (2010): "Parentesco trasnacional: intersecciones entre as teoría sobre migración y ámbito procreativo", en, Procreación, Crianza y Género: Aproximaciones antropológicas a la parentalidad, Barcelona: Promociones y Publicaciones Universitarias, pp. 119-140.

RUBIN, G. (1986): «El tráfico de mujeres: notas sobre la economía política del sexo», EN El género: la construcción cultural de la diferencia sexual, México, PUEGUNAM, pp. 35-98.

SAN MIGUEL, M. (2015): "Efectos en las subjetividades contemporáneas de la desigualdad y de las relaciones de poder entre los modelos de masculinidad y feminidad", en Mujeres, hombres, poder: subjetividades en conflicto, Madrid: Editorial Traficantes de sueños, pp. 151-174. SOLÉ, C. (2000). La inmigración femenina en la era de la globalización, en Mujer y migración en el mediterráneo occidental, España, Editorial Icaria., pp. 241-253. 
SMITH, D. (2012): "El punto de vista (standpoint) de las mujeres: Conocimiento encarnado versus relaciones de dominación", en Revista del CEIHM Temas de mujeres, $\mathrm{N}^{\circ} 8$, Año 8, pp. 5-27.

SMITH SILVA, D. (2014). "Representing and performing latina chicana mothering", en Mothers, Mothering and motherhood across cultural differences, Cánada, Editorial Demeter Press, pp. 229-254.

STEVENS, E. (1974): "El marianismo: la otra cara del machismo en américa latina". En: Revista Diálogos: Artes, letras ciencias humanas, Volumen 10, N 1 (55). Pp. 17-24.

STOLCKE, V. (2010): “¿Qué tiene que ver el género con el parentesco?", en Procreación, Crianza y Género: Aproximaciones antropológicas a la parentalidad, Barcelona, Promociones y Publicaciones Universitarias, pp. 319334.

TRUJILLO, M.; RIVERA, P. Y ALMEDA, E. (2015): Desde el conocimiento situado hacia el feminismo decolonial: Nuevas perspectivas de análisis para el estudio de la monomarentalidad e inmigración latinoamericana, disponible en http://revistes. ub.edu/index.php/oximora/article/view/14517 [Consulta 19-1-2016]

TUBERT, S. (1991): Mujeres sin sombra: Maternidad y tecnología, España, Ediciones Siglo Veintiuno.

VALLES, M. (2009): Entrevistas cualitativas, Cuadernos metodológicos del Centro de Investigaciones sociológicas, CIS, número 32, España, Publidisa.

WALTERS, M. (1996): "Hogares de progenitor único encabezados por mujeres" en La red de lo invisible, España, Editorial Paidos Ibérica, pp. 318-337.

ZENTGRAF, K. (2002). "Immigration and Women's Empowerment: Salvadorans in Los Angeles", disponible en, http://www.jstor.org/stable/3081952 [Consulta 7-112015] 
